\title{
Letter from the Dean of the College of Education
}

I am privileged to be among the first readers of this issue of JTLPS. The set of strong papers examine the issues of diversity in American education. They cannot be more timely as the country is pulled up short to face its persistent inequities and injustices. The number of early-career scholars who comprise the authors in this issue bring in their personal stories, their obvious passion and the honest desire to figure out large problems. This is a mix of empirical studies and theoretical pieces, each with its unique voice and scholarly approach.

The College of Education at Sac State is proud to support a journal that gives a platform to emerging scholars. This is a lot more open, less elitist enterprise than the top academic journals. Its focus is developmental, embracing, encouraging. The editor spends much time discussing paper revisions and improvements. The result of this collaboration is a set of very good papers with a unique flavor. I hope you will enjoy the reading as much as I did.

\author{
Alexander M. Sidorkin \\ Dean, College of Education \\ California State University, Sacramento
}

